\title{
A Multiband Filter for Multistandards Wireless Communications Receivers
}

\author{
Ali OTHMAN, Rim BARRAK, Mohamed MABROUK \\ GRESCOM Research Laboratory, Higher School of Communications of Tunis (SUPCOM), \\ University of Carthage, City of Communications Technologies, 2083 El Ghazala, Ariana, Tunisia \\ $\{$ ali, rim\}@ supcom.tn, mohamed.mabrouk@isetcom.tn \\ Submitted February 24, 2017 / Accepted November 13, 2017
}

\begin{abstract}
A new topology for a multiband filter suitable for multistandard and multiband mobile terminals is proposed. This filter named MultiCrossed Open Stubs (MCOS) is based on the wideband Quarter-Wave Short Circuited Stubs (QWSCS) topology and consists of open stubs connected together with the main transmission line via a multicross junction. This technique allows division the wide bandpass response into several subbands by means of open stub transmission zeros. Full synthesis of the MCOS filter using $A B C D$ matrices and its application to GSM, GPS, UMTS, LTE, and Wi-Fi standards using FR4 microstrip technology are presented. Scattering (S) parameters simulations and measurements show good agreement according to standard specifications in terms of center frequencies and bandwidths. The achievable return losses for all bands are higher than $10 \mathrm{~dB}$, and transmission losses are between $3.9 \mathrm{~dB}$ and $6 \mathrm{~dB}$. The proposed multiband filter topology is well suited for the implementation of reconfigurable multiband filters.
\end{abstract}

\section{Keywords}

Microstrip technology, multiband filters, multistandard receivers, S-parameters, stubs

\section{Introduction}

Wireless communication services have known a great progress up to now. These services are provided to users over radio communication systems operating with different radio standards and transmission techniques. Hence, mobile terminals should have the capability to work correctly with several radio standards across different frequency bands and align with the required specifications for each standard. The existing technology employed in actual mobile terminals consists of assembling multiple sets of hardware in parallel in the same terminal; each one is dedicated to operate with a specific standard. The trend of telecommunication circuits design is the development of radio transceivers able to work simultaneously with different standards (multistandard) in several bands (multiband). The most challenging part of the multistandard and multiband transceiver hardware is the RF circuits. At the receiver side, the multiband sampling architecture is the most appropriate one for such an application [1]. In this architecture, RF filters should be selective enough to select the required bands and reject out-of-band signals susceptible to overlap with the required signals after subsampling. In this paper, we focus on RF filters which are considered as important components in multiband sampling receivers, because stringent conditions have to be taken into account in order to ensure correct extraction of the desired signals.

By referring to the literature, there are many papers dealing with multiband RF filters [3-11]. The designed multiband filters are based on several techniques for creating multiband response. The most popular ones are the stepped impedance resonators (SIR), the stub loaded resonators (SLR), the multimode resonators (MMR), and the multi-passband resontaors assembling. A dualband filter using three open ended shunt stubs is presented in [12]. In [3], the designed quint-band filter is based on coupled tri-mode stub-loaded stepped-impedance resonators. In [6], the designed double layered substrate quintband filter is based on three coupled pairs of stepped-impedance resonators on the top and middle metal layer, and two pairs of slot uniformimpedance resonators on the bottom metal layer. In [11], the designed sext-band filter is based on twelve coupled semi-lumped resonators, each one is designed to operate at a specific center frequency. All these filters present different constraints which are mainly related to the achievable bandwidths, the closeness of frequency bands and the increased size when other pass-bands are to be addressed. Also, these filters are not dedicated for wireless applications, such as Wireless Local Area Network (WLAN) or Long Term Evolution (LTE) standards, which impose severe constraints on multiband center frequencies bandwidths and out-of-band attenuations. These specifications are important in order to get proper operation because the filter will limit the signals passing through the receiver to those permitted and stop unwanted signals at specified frequencies as noted in the standards requirements. Leaving these unwanted signal unwell filtered 
will cause receiver performances degradation of the receiver like circuits saturation, distortion, etc., leading to operation failure. As a contribution in this field, we present in this paper a new multiband filter topology named "MultiCrossed Open Stubs (MCOS)" and based on a "Quarter-Wave Short Circuited Stubs (QWSCS)" wideband filter [13] in which we divide its passband into sub-bands by means of open stubs. We apply the proposed filter to design a five-band filter selecting GSM [15], GPS [16], LTE [17], UMTS [18], and Wi-Fi [19].

This paper is organized as follows: after this introduction, the proposed filter topology and synthesis equations are developed in Sec. 2. The next section provides the design and the S-parameter simulation of a five-band filter for GSM, GPS, UMTS, LTE, and Wi-Fi standards. Measurement results and comparison with other works are presented in Sec. 4.

\section{Proposed Multiband Filter Topol- ogy}

The proposed multiband MCOS filter is based on a second order QWSCS bandpass filter [13] (Fig. 1).

It is composed by two shunt quarter wavelength shortcircuited stubs interconnected by a quarter wavelength line. This filter presents two transmission zeros, one at 0 and the other at $2 f_{0}$, where $f_{0}$ is the center frequency. The impedance values of the short-circuited stubs $\left(Z_{1}, Z_{2}\right)$ and the middle line $\left(Z_{1,2}\right)$ are provided in [13]. In the proposed topology, the middle line is divided into two equal portions and interconnected to $N$ multicrossed open stubs as depicted in Fig. 2. Each stub provides a transmission zero, thus creating a multiband response with $N+1$ maximum sub-bands. $Z_{\mathrm{i}}$ and $\theta_{\mathrm{i}}(i=3, \ldots, N+2)$ denote respectively the characteristic impedance and the electrical length of the $i^{\text {th }}$ stub. The center frequencies of sub-bands are taken as the average of the two delimiting transmission zeros, i.e., the center frequency of the $j^{\text {th }}$ band $\left(f_{0 j}\right)$ is the average value of the zeros frequencies $\left(f_{\mathrm{z}(j+2)}\right.$ and $\left.f_{\mathrm{z}(j+3)}\right)$, i.e., $f_{0 j}=\left(f_{\mathrm{z}(j+2)}+f_{\mathrm{z}(j+3)}\right) / 2$.

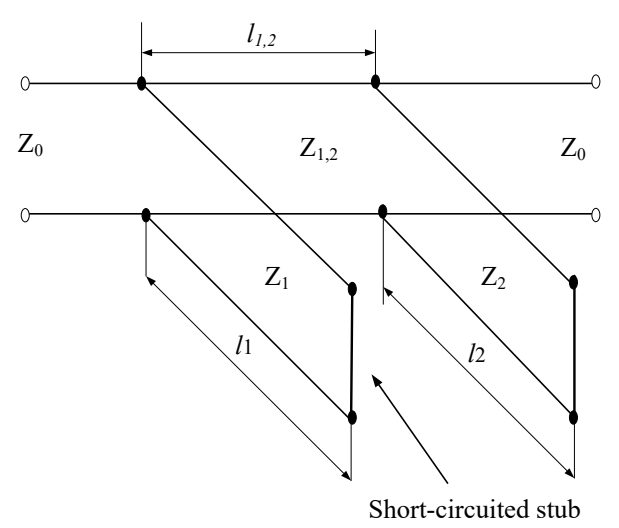

Fig. 1. Second order QWSCS bandpass filter.

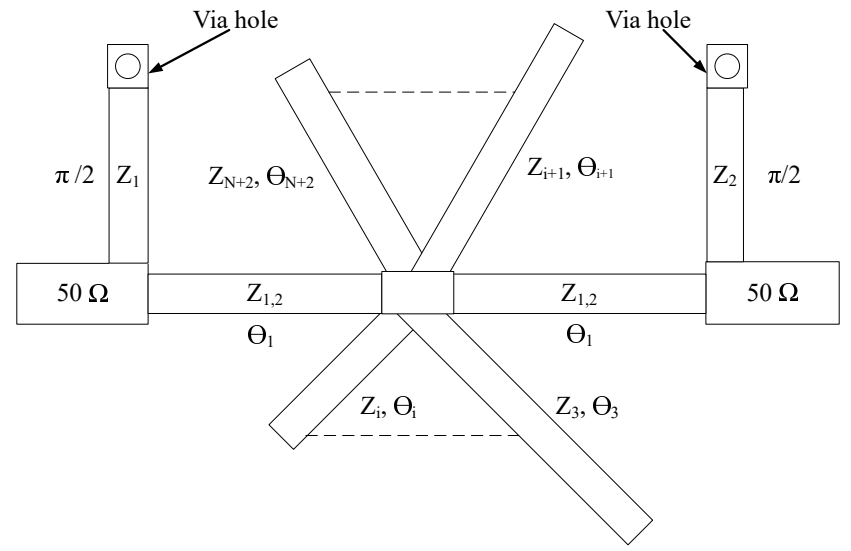

Fig. 2. Proposed Multicrossed open stubs topology.

The filter parameters $\left(Z_{i}, \theta_{i}\right)$ are obtained when the ABCD matrix of the middle line in the QWSCS filter and the equivalent $\mathrm{ABCD}$ matrix of the MCOS structure are equal. The $A B C D$ matrix of the middle quarter wavelength line $(\theta=\pi / 2)$ shown in Fig. 1 and having characteristic impedance $Z_{1,2}$ is given by (1).

$$
\left(\begin{array}{ll}
A & B \\
C & D
\end{array}\right)=\left(\begin{array}{cc}
\cos \theta & \mathrm{j} Z_{1,2} \sin \theta \\
\frac{\mathrm{j} \sin \theta}{Z_{1,2}} & \cos \theta
\end{array}\right)=\left(\begin{array}{cc}
0 & \mathrm{j} Z_{1,2} \\
\frac{\mathrm{j}}{Z_{1,2}} & 0
\end{array}\right) .
$$

The ABCD matrix of the MCOS structure shown in Fig. 2 is given by:

$$
\begin{array}{r}
\left(\begin{array}{ll}
A & B \\
C & D
\end{array}\right)=\left(\begin{array}{cc}
\cos \theta_{1} & \mathrm{j} Z_{1,2} \sin \theta_{1} \\
\frac{\mathrm{j} \sin \theta_{1}}{Z_{1,2}} & \cos \theta_{1}
\end{array}\right) \times \prod_{i=3}^{N+2}\left(\begin{array}{cc}
1 & 0 \\
\frac{\mathrm{j} \tan \theta_{i}}{Z_{i}} & 1
\end{array}\right) \\
\times\left(\begin{array}{cc}
\cos \theta_{1} & \mathrm{j} Z_{1,2} \sin \theta_{1} \\
\frac{\mathrm{j} \sin \theta_{1}}{Z_{1,2}} & \cos \theta_{1}
\end{array}\right) .
\end{array}
$$

Replacing $\theta_{1}$ by $\frac{\pi}{4}$, the equality of the two systems (1) and (2) gives:

$$
\sum_{i=3}^{N+2} \frac{\tan \theta_{i}}{Z_{i}}=0
$$

The relation above is valid for any impedance value in the limited range of the fabrication process. But in order to reduce discontinuity effects relative to junction in the middle caused by connection of different stubs widths, we recommend to assemble electrical lengths of stubs into two groups: one has a positive tangent sum and the other has a negative tangent sum, in a manner to get a ratio as close as possible to -1 with equality of their impedances. Then, we set one group impedance to a desired value and we determine the other one. This is detailed in (4)-(6).

$$
\begin{gathered}
\tan \theta_{j}+\tan \theta_{p}+\cdots>0 \text { and } \tan \theta_{r}+\tan \theta_{s}+\cdots<0, \\
\frac{\tan \theta_{j}+\tan \theta_{p}+\ldots}{\tan \theta_{r}+\tan \theta_{s}+\ldots} \approx-1, \\
\frac{\tan \theta_{j}+\tan \theta_{p}+\ldots}{Z_{j}}=-\left(\frac{\tan \theta_{r}+\tan \theta_{s}+\ldots}{Z_{r}}\right) .
\end{gathered}
$$


The electrical lengths of the stubs are obtained by (7), where $f_{\mathrm{z} i}$ is the $i^{\text {th }}$ transmission zero $(i=3, \ldots, N+2)$.

$$
\theta_{i}=\frac{\pi}{2} \frac{f_{0}}{f_{\mathrm{zi}}}
$$

In order to get the desired subbands, we propose that stubs must be putted in an alternating manner from bottom to top with respect to the horizontal middle line, and beginning with the longest stub from the output side of the filter to its input port.

It is worth to be noted that if there is a desired band between $f_{\max }$ and the first harmonic of the first transmission zero $\left(3 f_{\mathrm{z} 3}\right)$, an additional stub must be added to give rise to a transmission zero before $3 f_{\mathrm{z} 3}$ in order to keep the synthesis equations valid.

With $\mathrm{N}$ stubs, we get $N+1$ bands: the first band is obtained by the transmission zeros at 0 and $f_{\min }$ corresponding to the longest stub, the last band is obtained by the transmission zeros at $f_{\max }$ corresponding to the shortest stub and $2 f_{0}$ and the other $N-1$ bands are obtained by the remaining transmission zeros. Since, there is no control on the first and the last bands, $N$ cross-connected stubs would give rise to $N-1$ controlled bands.

The proposed design methodology is as follow:

1. Given $N$ bandpass desired responses, synthesize a wide bandpass filter response according to [13] centered on $f_{0}$ which is corresponding to the middle frequency band

2. Determine the transmission zeros frequencies in accordance with the $N$ bandpass desired center frequencies. Choose these frequencies as the average values of the delimiting center frequencies $\left(f_{z i}=\left(f_{0(i-3)}+f_{0(i-2)}\right) / 2\right)$

3. Calculate the corresponding stub electrical lengths according to (7)

4. According to bandwidth requirements for each band, synthesize the stub impedances using (3) and verify the response by an electrical simulation

5. Connect the stubs via a multicross junction to obtain the desired bands in the manner cited above

6. Optimize the filter in a full-wave simulator in order to obtain the required multibandpass response

The proposed filter design methodology is based on desired center frequencies; bandwidths control is not included in the synthesis equations. Therefore, impedance stubs optimization is required to obtain the desired multiband response.

\section{Design of a Five Bands Filter for GSM, GPS, LTE, UMTS and Wi-Fi Standards}

The proposed design methodology developed in the previous section is applied to design a five-band filter for the standards: GSM, GPS, UMTS, LTE, and Wi-Fi. Table 1 shows the standards specifications.

The first step is to design the wideband filter using a $2^{\text {nd }}$ order Butterworth approximation having a center frequency $f_{0}=1.58 \mathrm{GHz}$, which corresponds to the GPS band, and a bandwidth of $2 \mathrm{GHz}$. This leads to the following parameters: $Z_{1}=Z_{2}=90 \Omega$ and $Z_{1,2}=50 \Omega$. The second step is to determine the transmission zero frequencies in accordance with the frequency response prototype. The bands are formed as follows: GSM band: stub $\mathrm{N}^{\circ} 3$ and $\mathrm{N}^{\circ} 4$, GPS band: stub $\mathrm{N}^{\circ} 5$ and $\mathrm{N}^{\circ} 6$, LTE band: stub $\mathrm{N}^{\circ} 6$ and $\mathrm{N}^{\circ} 7$, UMTS band: stub $\mathrm{N}^{\circ} 7$ and $\mathrm{N}^{\circ} 8$ and WiFi band: stub $\mathrm{N}^{\circ} 8$ and $\mathrm{N}^{\circ} 9$. We selected: $f_{\mathrm{z} 3}=0.852 \mathrm{GHz}$, $f_{\mathrm{z} 4}=1.354 \mathrm{GHz}, f_{\mathrm{z} 5}=1.475 \mathrm{GHz}, f_{\mathrm{z} 6}=1.738 \mathrm{GHz}$, $f_{\mathrm{z} 7}=2.069 \mathrm{GHz}, f_{\mathrm{z} 8}=2.299 \mathrm{GHz}$ and $f_{\mathrm{z} 9}=2.52 \mathrm{GHz}$. The next step is calculate the stub electrical lengths using equation (4). This leads to the following parameters: $\theta_{3}=166.9^{\circ}$, $\theta_{4}=105^{\circ}, \theta_{5}=96.4^{\circ}, \theta_{6}=81.8^{\circ}, \theta_{7}=68.72^{\circ}, \theta_{8}=61.85^{\circ}$, $\theta_{9}=56.43^{\circ}$. We increased the $4^{\text {th }}$ transmission zero to eliminate a parasitic band between GSM and GPS. For simplification, we assigned two different values to the characteristic impedance of the stubs. A high impedance value allows obtaining a higher bandwidth. We set the characteristic impedance of the $3^{r d}, 4^{\text {th }}, 7^{\text {th }}, 8^{\text {th }}$ and $9^{\text {th }}$ stubs to $90 \Omega$, then we calculated the remain impedance value for the $5^{\text {th }}$ and $6^{\text {th }}$ stubs using (3). We found $Z_{5}=Z_{6}=89 \Omega$.

In order to avoid the use of via holes due to their parasitic effects, we can replace them by radial stubs. For microstrip implementation, we use FR4 substrate with relative permittivity $\varepsilon_{\mathrm{r}}=4.4$, loss tangent $\tan \delta=0.018$, height $H=1.6 \mathrm{~mm}$ and copper material as conductor with a thickness $t=35 \mu \mathrm{m}$. Figures 3 and 4 show respectively the layout of the designed filter and its $\mathrm{S}$ parameter simulation.

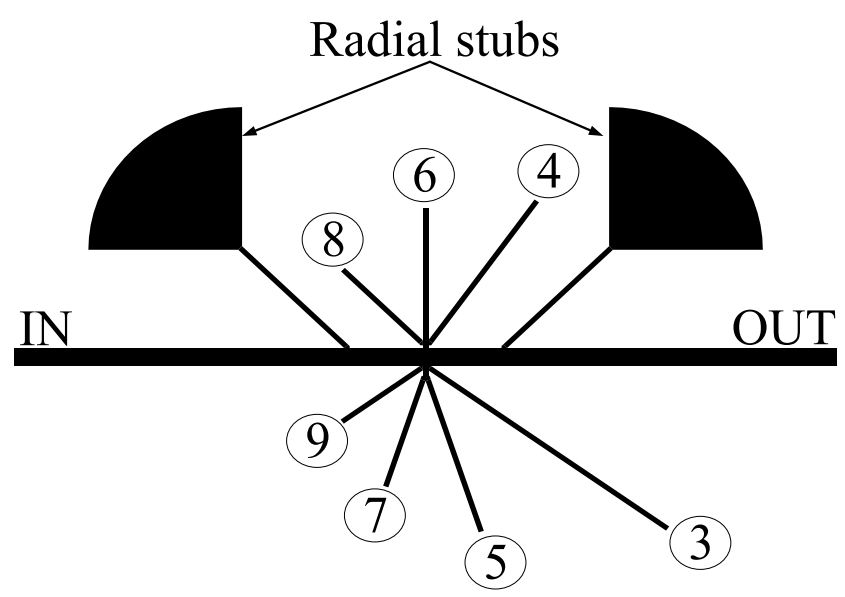

Fig. 3. Layout of the MCOS filter. 


\begin{tabular}{|c|c|c|c|c|c|}
\hline \multirow[b]{2}{*}{ Standards } & \multicolumn{5}{|c|}{ Specifications } \\
\hline & $f_{\mathbf{c}}{ }^{1}[\mathrm{GHz}]$ & $\mathbf{B W}^{2}[\mathrm{MHz}]$ & $f_{\mathrm{s} 1}{ }^{3}[\mathrm{GHz}]$ & $f_{\mathbf{s} 2}{ }^{3}[\mathrm{GHz}]$ & $\boldsymbol{A}_{\mathbf{s}}{ }^{4}[\mathrm{~dB}]$ \\
\hline GSM & 0.9475 & 25 & 0.915 & 0.98 & 23 \\
\hline GPS (L1) & 1.576 & 4 & - & - & - \\
\hline LTE & 1.8425 & 75 & $\begin{array}{c}1.72 \\
1.745\end{array}$ & $\begin{array}{c}1.965 \\
1.94\end{array}$ & $\begin{array}{l}29 \\
14\end{array}$ \\
\hline UMTS & 2.14 & 60 & $\begin{array}{c}2.025 \\
2.05\end{array}$ & $\begin{array}{c}2.255 \\
2.23\end{array}$ & $\begin{array}{l}29 \\
14\end{array}$ \\
\hline Wi-Fi & 2.441 & 83.5 & 2 & 3 & 17 \\
\hline
\end{tabular}

Tab. 1. Standards specifications.

Table 2 presents the electrical performances of the MCOS filter. By referring to Tab. 1, we remark that there is a good agreement with the required specifications for different standards with a little center frequency shift.

The proposed designed filter holds one pole for each band. To improve the transition band selectivity, higher order filter can be addressed by duplicating the same structure in a suitable manner. For our case, and to make a second order MCOS filter, an obvious technique can be implemented

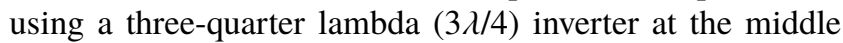
of the first and the fifth center frequencies, to keep a safe uncoupling distance between the two structures. Unlike the case of a dualband filter in which this solution gives good results [12], in our concerns five bands are addressed, which makes the desired multiband response difficult to achieve and might require some other adjustments like the use of stepped impedance lines [14].

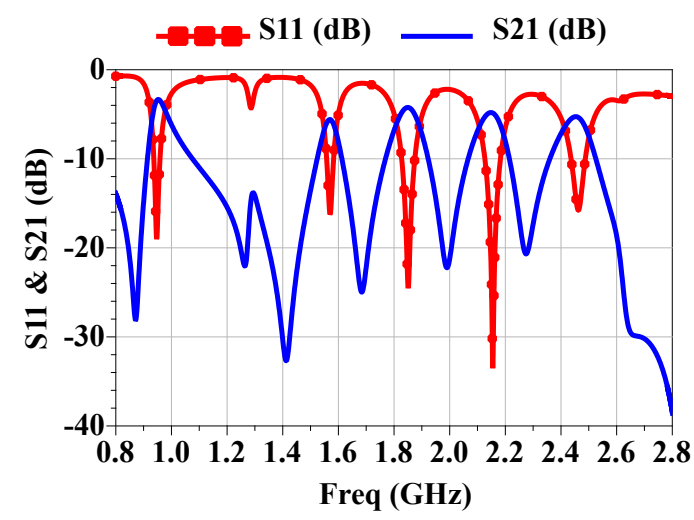

Fig. 4. $S$ parameters simulations of the MCOS filter.

\begin{tabular}{|c|c|c|c|c|}
\hline \multirow{2}{*}{ Standards } & \multicolumn{4}{|c|}{ Performances } \\
\cline { 2 - 5 } & $\boldsymbol{f}_{\mathbf{c}}{ }^{1}[\mathrm{GHz}]$ & $\mathbf{B W}^{2}[\mathrm{MHz}]$ & $\mathbf{I L}^{3}[\mathrm{~dB}]$ & $\mathbf{R L}^{4}[\mathrm{~dB}]$ \\
\hline GSM & 0.968 & 69 & 3.6 & 7.3 \\
\hline $\begin{array}{c}\text { GPS } \\
\text { (L1) }\end{array}$ & 1.558 & 68 & 4.9 & 19.9 \\
\hline LTE & 1.846 & 97 & 3.9 & 21.7 \\
\hline UMTS & 2.14 & 119 & 3.9 & 17.5 \\
\hline Wi-Fi & 2.431 & 122 & 4.4 & 17.7 \\
\hline
\end{tabular}

${ }^{1} f_{\mathrm{c}}$ : Center frequency ${ }^{2} \mathrm{BW}$ : Bandwidth

${ }^{3}$ IL: Insertion loss ${ }^{4}$ RL: Return loss

Tab. 2. Electrical performances of the MCOS filter.

\section{Realization and Measurement Re- sults}

Following the simulation, the optimized filter layout was fabricated as shown in Fig. 5. Its size is $137.15 \mathrm{~mm}$ x $90 \mathrm{~mm}$. A comparison of measurement and simulation results is presented in Fig. 6 including insertion loss, return loss and group delay. Table 3 compares the proposed filter with previous multiband BPFs.

The measured loaded quality factors are as follows: for GSM band, $Q=10.8$; for GPS band, $Q=21.1$; for LTE band, $Q=15.6$; for UMTS band, $Q=18.18$; for Wi-Fi band, $Q=18.38$. The required loaded quality factors are as follows: for GSM band, $Q=37.9$; for GPS band, $Q=394$; for LTE band, $Q=24.56$; for UMTS band, $Q=35.6$; for Wi-Fi band, $Q=29.2$. We remark that there is a shift between the required and measured loaded quality factor but it remains quite acceptable except for GPS band. This is due to the higher chosen impedance value $(90 \Omega)$ in order to guarantee the highest bandwidth value, which is relative to $\mathrm{Wi}-\mathrm{Fi}$ band. So, if we want to reduce the bandwidth, we should decrease this impedance until reaching the desired bandwidth checked by simulations. Also the sharing of common transmission zeros may be a disadvantage point, because if we want to control one passband bandwidth by controlling the adjacent transmission zeros frequencies instead or besides the impedance control, the two adjacent passband bandwidths will be varied.

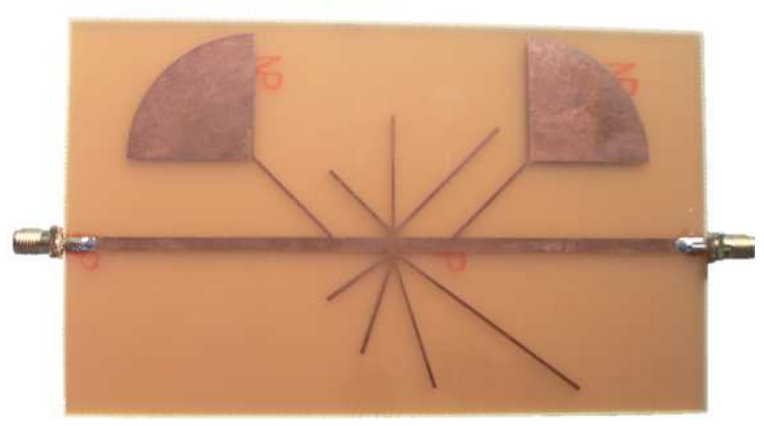

Fig. 5. Photo of the fabricated filter. 


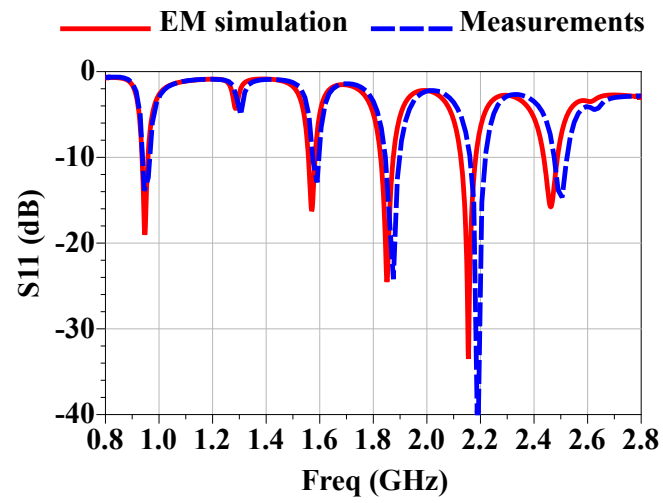

(a)

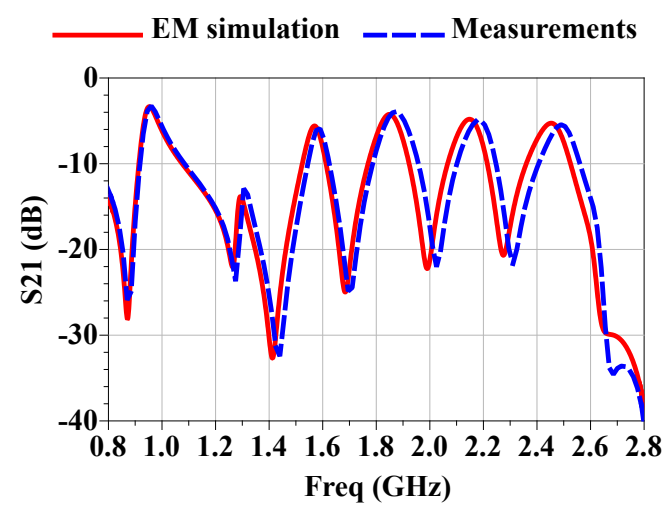

(b)

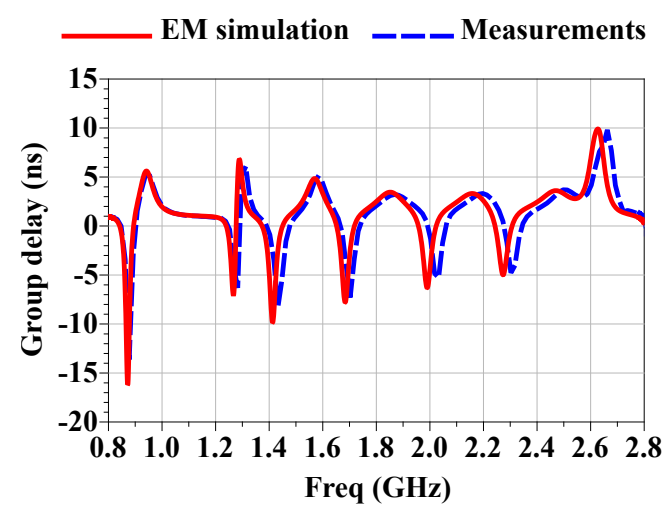

(c)

Fig. 6. $S$ parameters measurements: (a) $S_{11}$ (dB), (b) $S_{21}$ (dB), (c) group delay (ns).

Table 3 shows a comparison between the proposed filter performances and other works [3], [6], [11]. We remark that the achievable performances in terms of return losses and fractional bandwidths are comparable to those of the other works. However, the insertion losses are relatively high. In fact, in our design we used a low cost FR4 substrate with high loss tangent because we aimed here to present a proof of concept of the proposed idea. By comparing the proposed filter to the filter cited in [2] which uses the same FR4 substrate, it is clear that this filter has much better performances by exhibiting a maximum insertion loss of $6 \mathrm{~dB}$. To reduce the insertion loss a low loss substrate such as Rogers can be used. To further reduce the insertion loss we can use a superconducting material such as Yttrium barium cop- per oxide (YBCO) instead of conventional copper materials, which has a very low metal loss. Therefore, by reducing metal and dielectric losses, the overall insertion loss of the filter can be reduced. In our design, the insertion loss in the GPS band $(1.58 \mathrm{GHz})$ is relatively high compared to the other bands because the required bandwidth in this band is lower than the others. A wider bandwidth setting will result in a lower insertion loss. Indeed, the proposed filter has a length smaller than the others in [3], [11] and its size remains unchanged while increasing the number of bands, which is not the case for the other references cited in Tab. 3. Also, the presented filters are based on coupled resonators which limits the range of achievable bandwidths due to the realizable minimum and maximum coupling gap, however, in our case we have the possibility to obtain a wider range of bandwidths. Finally, the proposed filter has the capability of providing an easy reconfiguration process while dealing with the scope of reconfigurable multiband RF filters by adding tuning elements at the end of the stubs.

\section{Conclusion}

In this paper, we present a new topology and methodology to design a multiband filter suitable for multistandard and multiband receivers. The proposed methodology was applied to design a multiband filter covering five standards: GSM, GPS, UMTS, LTE, and Wi-Fi. S parameter EM simulation and measurements show good agreement in terms of center frequencies and bandwidths. We notice that the proposed filter, despite the difference between the used substrate, presents three advantages regarding the others: the first is the possibility of obtaining very close bands (frequency ratio) with a wide range of bandwidths, the second is the independence between the number of passbands and the size of the filter that remain unchanged, and the third is flexibility in design and simplicity in form which makes the filter suitable for reconfiguration process, which will be studied in future work in order to control the number of operating frequency bands and make it suitable for implementation in Software Defined Radios systems.

\section{Acknowledgments}

The authors would like to thank Dr. Ghalid Idir Abib, associate professor at "Télécom SudParis", for his contribution in the circuit realization.

\section{References}

[1] CRUZ, P., CARVAlHO, N. B., REMLEY, K. A. Designing and testing software-defined radios. IEEE Microwave Magazine, 2010, vol. 11, no. 4, p. 83-94. ISSN: 1527-3342. DOI: 10.1109/MMM.2010.936493

[2] SANI, M. M. A., KHAN, Z. I., RASHID, N. E. A., et al. Single ring dual-band bandpass filter with meander for $2.5 \mathrm{GHz}$ and $5.2 \mathrm{GHz}$. In Proceedings of the IEEE International RF and Microwave Conference. Malaysia, 2015, p. 22-26. DOI: 10.1109/RFM.2015.7587704 


\begin{tabular}{|c|c|c|c|c|c|}
\hline & [2] & [3] & [6] & [11] & Proposed filter \\
\hline Substrate & FR4 & Rogers RO4003 & RT/Duroid 5880 & $\mathrm{RO} 4003 \mathrm{C}$ & FR4 \\
\hline$H[\mathrm{~mm}] / \varepsilon_{r} / \tan \delta$ & 1.6/5.4/high & $0.508 / 3.38 / 0.002$ & $0.787 \& 0.508 / 2.2 / 0.0009$ & $1.524 / 3.55 / 0.0021$ & $1.6 / 4.4 / 0.018$ \\
\hline $\mathbf{P N}^{1}$ & 2 & 5 & 5 & 6 & 5 \\
\hline $\mathbf{C F}^{2}[\mathrm{GHz}]$ & $2.5 / 5.2$ & $\begin{array}{c}0.6 / 0.9 / 1.2 \\
1.5 / 1.8\end{array}$ & $\begin{array}{c}1.5 / 2.5 / 3.5 \\
4.5 / 5.8\end{array}$ & $\begin{array}{l}0.8 / 1.2 / 1.4 \\
1.8 / 2.2 / 2.5\end{array}$ & $\begin{array}{c}0.975 / 1.582 / 1.875 \\
2.175 / 2.482\end{array}$ \\
\hline $\mathbf{F B W}^{3}[\%]$ & $7.14 / 3.57$ & $\begin{array}{c}5.8 / 5.2 / 5.8 \\
8.2 / 8\end{array}$ & $\begin{array}{c}4.5 / 4.5 / 3.6 \\
4.5 / 2.7\end{array}$ & $\begin{array}{c}2.3 / 2.9 / 3.3 \\
3.2 / 2 / 2\end{array}$ & $\begin{array}{c}9.23 / 4.74 / 6.4 \\
5.5 / 5.44\end{array}$ \\
\hline $\mathbf{I L}^{4}[\mathrm{~dB}]$ & $8 / 11$ & $\begin{array}{c}2.8 / 2.9 / 2.9 \\
2.6 / 2.3 \\
\end{array}$ & $\begin{array}{c}1.5 / 1.8 / 0.9 \\
1.2 / 1.5 \\
\end{array}$ & $\begin{array}{c}2.9 / 2.34 / 2.59 \\
2.24 / 2.67 / 2.64 \\
\end{array}$ & $\begin{array}{c}3.9 / 6 / 3.9 \\
5 / 5.4 \\
\end{array}$ \\
\hline $\mathbf{R L}^{5}[\mathrm{~dB}]$ & $\begin{array}{l}>11 \text { for all } \\
\text { bands }\end{array}$ & $\begin{array}{l}>13 \text { for all } \\
\text { bands }\end{array}$ & $\begin{array}{l}>11 \text { for all } \\
\text { bands }\end{array}$ & $\begin{array}{l}>10 \text { for all } \\
\text { bands }\end{array}$ & $\begin{array}{l}>11 \text { for all } \\
\text { bands }\end{array}$ \\
\hline Size $[\mathrm{mm} \times \mathrm{mm}]$ & $30 \times 8$ & $171.1 \times 14.9$ & $35.3 \times 25.3$ & $171.8 \times 14.25$ & $137.15 \times 90$ \\
\hline
\end{tabular}

${ }^{1}$ PN: Passbands number $\quad{ }^{2}$ CF: Center frequency $\quad{ }^{3}$ FBW: Fractional Bandwidth $\quad{ }^{4}$ IL: Insertion loss

${ }^{5}$ RL: Return loss

Tab. 3. Comparison table of multiband bandpass filters.

[3] CHEN, C. F. Design of a compact microstrip quint-band filter based on the tri-mode stub-loaded stepped-impedance resonators. IEEE Microwave and Wireless Components Letters, 2012, vol. 22, no. 7, p. 357-359. ISSN: 1531-1309. DOI: 10.1109/LMWC.2012.2202894

[4] LI, X., WANG, H. An approach for multi-band bandpass filter design based on asymmetric half-wavelength resonators. Progress In Electromagnetics Research, 2013, vol. 140, p. 31-42. ISSN: 1559-8985. DOI: 10.2528/PIER13031504

[5] ZHANG, S., ZHU, L. Compact tri-band bandpass filter based on $\lambda / 4$ resonators with u-folded coupled-line. IEEE Microwave and Wireless Components Letters, 2013, vol. 23, no. 5, p. 258-260. ISSN: 1531-1309. DOI: 10.1109/LMWC.2013.2255868

[6] HSU, K. W., HUNG, W. C., TU, W. H. Compact quint-band microstrip bandpass filter using double-layered substrate. In Proceedings of the IEEE MTT-S International Microwave Symposium Digest (IMS). Seattle (USA), 2013, p. 1-4. DOI: 10.1109/MWSYM.2013.6697353

[7] MOHAMED, H. A., EL-SHAARAWY, H. B., ABDALlA, E. A., et al. A very compact novel multi-band BPF for recent mobile/satellite communication systems. Progress In Electromagnetics Research, 2014, vol. 50, p. 47-56. ISSN: 1937-8718. DOI: $10.2528 /$ PIERC14031307

[8] GAO, L., ZHANG, X. Y., HU, B. J., et al. Novel multistub loaded resonators and their applications to various bandpass filters. IEEE Transactions on Microwave Theory and Techniques, 2014, vol. 62, no. 5, p. 1162-1172. ISSN: 0018-9480. DOI: 10.1109/TMTT.2014.2314680

[9] LIU, H., LEI, J., GUAN, X., et al. Compact high-temperature superconducting filter using multimode stub-loaded resonator. IEEE Transactions on Applied Superconductivity, 2014, vol. 24, no. 2, p. 8-15. ISSN: 1051-8223. DOI: 10.1109/TASC.2014.2301753

[10] LIU, H., REN, B., GUAN, X., et al. Quad-band high-temperature superconducting bandpass filter using quadruple-mode square ring loaded resonator. IEEE Transactions on Microwave Theory and Techniques, 2014, vol. 62, no. 12, p. 2931-2941. ISSN: 0018-9480. DOI: 10.1109/TMTT.2014.2366147

[11] TU, W. H., HSU, K. W. Design of sext-band bandpass filter and sextaplexer using semilumped resonators for system in a package. IEEE Transactions on Components, Packaging and Manufacturing Technology, 2015, vol. 5, no. 3, p. 265-273. ISSN: 2156-3950. DOI: $10.1109 /$ TCPMT.2014.2387198
[12] QUENDO, C., RIUS, E., PERSON, C. An original topology of dualband filter with transmission zeros. In Proceedings of the IEEE MTTS International Microwave Symposium Digest (IMS). Philadelphia (USA), 2003, p. 1093-1096. DOI: 10.1109/MWSYM.2003.1212559

[13] HONG, J. S., LANCASTER, M. J. Microstrip Filters For RF/Microwave Applications. New York (USA): John Wiley \& Sons, 2001. ISBN: 0-471-38877-7

[14] QUENDO, C., RIUS, E., MANCHEC, A., et al. Planar tri-band filter based on dual behavior resonator (DBR). In Proceedings of the European Microwave Conference (EuMC). Paris (France), 2005, p. 1-4. DOI: 10.1109/EUMC.2005.1608845

[15] Digital Cellular Telecommunications System (Phase 2+); Radio Transmission and Reception. ETSI. GSM 05.05 version 8.5.1 release 1999, 2000.

[16] Global Positionning System Wing (GPSW) Systems Engineering \& Integration. ETSI. IS-GPS-200E, 2010.

[17] LTE; Evolved Universal Terrestrial Radio Access (E-UTRA); User Equipment (UE) Conformance Specification; Radio Transmission and Reception; Part 1: Conformance Testing. ETSI. 3GPP TS 36.521-1 version 10.3.0 release 10, 2012.

[18] Universal Mobile Telecommunications System (UMTS); UE Radio Transmission and Reception (FDD). ETSI. 3GPP ts 25.101 version 5.2.0 release 5, 2002.

[19] IEEE802.11g. Part 11: Wireless LAN Medium Access Control (MAC) and Physical Layer (PHY) Specifications, Amendment 4: Further Higher Data Rate Extension in the $2.4 \mathrm{GHz}$ Band. IEEE std. 3GPP TS 25.101 version 5.2.0 Release 5, 2003.

\section{About the Authors...}

Ali OTHMAN was born in Gabes, Tunisia, in 1986. He received the B.S. degree in networks and communications engineering from the national school of engineering of Gabes (ENIG) and the M.S. degree in telecommunications from the higher school of communications of Tunis (SUPCOM) in 2010 and 2013, respectively. He is currently pursuing his Ph.D. at SUPCOM university in the field of the design of multiband tunable RF filters for software defined radio (SDR) and cognitive radio (CR) receivers. His research interests include RF/microwave circuits and systems, electrical and electronic engineering. 
Rim BARRAK (IEEE member), received the B.S. degree in Circuits and Systems from the "Ecole Polytechnique de Tunisie (EPT)", Tunis, Tunisia, in 2000, and the M.S. degree in telecommunications from the "Ecole Polytechnique de Montreal (EPM)", QC, Canada, in 2002 and the Ph.D. degree in communication and information technologies from "Ecole Supérieure des Communications de Tunis (Sup'Com)", Tunis, Tunisia in 2007. She is currently an assistant professor in Telecommunications and member of GRESCOM research laboratory at SUP'COM. Her research interests are in the areas of software radio receiver architectures, design of reconfigurable multiband RF filters and antennas and design of intelligent RF receivers for wireless communication and GNSS positioning systems. She has authored and co-authored over 40 scientific publications in international journals and conferences.

Mohamed MABROUK (IEEE Senior Member \# 00370239), was born in 1961 in Aouadna, Menzel Chaker, Sfax, Tunisia. He received the DEA and $\mathrm{PhD}$ Thesis degrees in OOM ("Optique Optoélectronique et Microondes") from Institut National Polytechnique of Grenoble (INPG), France in 1988 and 1991 respectively. His doctoral research concerned RF and Microwave Test and Measurements using TRL calibration for MMIC characterization between 2 and $18 \mathrm{GHz}$. From 1995-1998, he worked for Teradyne, Inc. (Paris office and Boston, USA) as RF/Microwave
Applications Engineer, where he developed several ATE turn key RF test solutions and dedicated trainings for European Semiconductors manufacturers. Since 1999, he has been an Assistant Professor and the head of Telecommunications department (40 permanent higher education Teachers and 15 Engineers) and teaching RF and Microwave devices, Transceiver equipments and RF/Microwave Measurements at ISETCOM of Tunis, Tunisia. He is currently Associate Professor and the head of Tunable RF Devices and Integration Team, GRESCOM Research Laboratory (SUPCOM de Tunis). His current research interests include RFID applications, RF and UWB Filters, Phase Shifters, integrated printed antennas characterization and RF/Microwave non-linearities measurements. Mohamed Mabrouk authored book chapter "RF and Microwave Test of MMICs: from Qualification to Mass Production", in "Advances in Monolithic Microwave Integrated Circuits for Wireless Systems: Modeling and Design Technologies", IGI Global Publishing, Hershey, PA (USA), September 2011. He is author and co author of over 70 papers in journals and conferences. M. Mabrouk received "Habilitation á Diriger les Recherches, HDR" (Tunisian National Authorization Degree for Research Supervising) in Telecommunications from the "Ecole Polytechnique de Tunisie (EPT)". M. Mabrouk is the supervisor of Master of Science degrees (four discussed) and six $\mathrm{PhD}$ thesis (four discussed and tow ongoing). 